attention. L-Carnitine is a dietary constituent and is non-toxic: on the theory that part of the disorder in hyperlipidaemia is the result of deficiency of L-carnitine it had been given as a supplement with some biochemical improvement. Compactin is the product of an exhaustive Japanese review of microbial products to find an inhibitor of liver and intestinal cholesterol syntheses. It is extremely potent, being effective in a dose of 15-30 mg daily in hypercholesterolaemia. Efficacy, safety, and clinical usefulness were being tested. Probucol has recently been introduced into Britain, having been available in the United States for three years. It is palatable and moderately hypocholesterolaemic, but the fact that it lowers HDL may limit its usefulness.

What does all this mean for the physician? Clearly there is no place for indiscriminate prophylactic drug treatment in the general community, and health education should focus on cigarette smoking, prudent diet, and screening for hypertension. For the individual with a poor personal or family history, or with appreciable hyperlipidaemia, treatment should invariably be supervised from a specialist clinic-if some of the mistakes of the past are to be avoided.

1 The Coronary Drug Project Research Group. Clofibrate and niacin in coronary heart disease. $\mathcal{F} A M A 1975 ; 231: 360-81$.

2 The Coronary Drug Project Research Group. Gallbladder disease as a side effect of drugs influencing lipid metabolism. Experience in the Coronary Drug Project. $N$ Engl $\mathcal{F}$ Med 1977;296:1185-7.

${ }^{3} \mathrm{~A}$ report from the Committee of Principal Investigators. A co-operative trial in the primary prevention of ischaemic heart disease using clofibrate. Br Heart $\mathcal{F} 1978 ; 40: 1069-1118$.

4 Miller GJ, Miller NE. Plasma-high-density-lipoprotein concentration and the development of ischaemic heart disease. Lancet 1975 ; :16-9.

${ }^{5}$ Angelin B, Einarsson K, Leijd B. Biliary lipid composition during treatment with different hypolipidaemic drugs. Eur $\mathcal{F}$ Clin Invest 1979;9: 185-90.

\section{Anaesthesia for patients with coronary disease}

A patient who has had a recent myocardial infarction is at risk if he needs general anaesthesia. About one-third of patients operated on within three months of an infarct develop a reinfarction in the first postoperative week, and at least half of them die. ${ }^{1}$ The incidence of reinfarction falls to around $5 \%$ once six months or more have elapsed. The risks are increased when surgery is prolonged and by operations within the thorax or upper abdomen but are independent of the nature of the anaesthetic. ${ }^{2}$

In absolute numbers, a more important problem is the fate of patients with ischaemic heart disease who have not suffered recent infarction. Goldman $e t a l^{3}$ looked at the frequency of cardiac complications after non-cardiac surgery in 1001 patients over 40 years old. Of these, 269 were found to have ischaemic heart disease; but, whereas stable angina, old myocardial infarction recognised historically or electrocardiographically, and ST-segment and T-wave changes were found to be of minimal importance in a multifactorial analysis of cardiac risk, in contrast myocardial infarction within six months and rhythm disturbances were high-risk factors. There were 19 cardiac deaths and 39 life-threatening cardiac complications during or after surgery in the group as a whole, and over half of these events occurred in the high-risk patients.
How can the anaesthetist reduce the hazards of anaesthesia and surgery for patients with ischaemic heart disease ? $^{4-6}$ Preoperative recognition is the first essential, and evidence from the clinical history is often more reliable than reliance on the electrocardiogram. Treatment with hypotensive drugs and beta-adrenergic blocking agents should be continued up to the time of operation and restarted afterwards in all but exceptional cases. During anaesthesia unnecessary cardiac work should be kept to a minimum by limiting increases in the heart rate and the blood pressure. The product of heart rate and systolic arterial blood pressure provides a useful index of myocardial oxygen consumption. ${ }^{7}$ Hypotension must also be avoided since coronary perfusion depends on the difference between the aortic and ventricular diastolic pressures. Overdistension of the heart is disadvantageous not only because it decreases coronary perfusion but also because it increases ventricular systolic tension. The anaesthetist should maintain satisfactory arterial oxygenation and keep the carbon dioxide tension as near normal as possible. ${ }^{8} \mathrm{~A}$ packed cell volume a little below the accepted normal figure may be beneficial in patients with ischaemic heart disease, but the increased cardiac output associated with both acute and chronic anaemia is detrimental.

If these recommendations are to be fulfilled patients need detailed monitoring during anaesthesia, and some of the techniques accepted as routine during cardiac surgery should be applied when patients with cardiac disease require operations of any kind. An electrocardiogram is essential, preferably recording from a precordial rather than a standard limb lead. ${ }^{9}$ Measurement of the central venous pressure may not provide useful information about the filling pressure of the left ventricle, but it should prevent gross errors of transfusion. More invasive monitoring ${ }^{10}$ - using a radial arterial cannula and, possibly, a pulmonary arterial catheter-is probably justified for patients who need surgery soon after a myocardial infarct. These aids make adverse haemodynamic changes more quickly recognisable, and improve the accuracy of both the selection and the control of treatment.

Monitoring should extend throughout the early postoperative period if maximum benefit is to be achieved. The peak incidence of reinfarction is on the third postoperative day, ${ }^{2}$ when myocardial viability is threatened by hypoxaemia, hypercoagulability, dehydration, increased metabolic demand, and the biochemical sequelae of acute starvation. Safety depends on vigilance so, ideally, high-risk patients should be kept in an intensive care unit for at least three days after operation as a safeguard against cardiovascular complications.

1 Steen PA, Tinker JH, Tarhan S. Myocardial reinfarction after anesthesia and surgery. F $A M A$ 1978;239:2566-70.

2 Tarhan S, Moffitt EA, Taylor WF, Giuliani R. Myocardial infarction after general anesthesia. $\mathcal{F} A M A 1972 ; 220: 1451-4$.

${ }^{3}$ Goldman L, Caldera DL, Nussbaum SR, et al. Multifactorial index of cardiac risk in noncardiac surgical procedures. $N$ Engl $\mathcal{F}$ Med 1977; 297:845-50.

${ }^{4}$ Smith G. The coronary circulation and anaesthesia. Br f Anaesth 1976; 48:933-4.

${ }^{5}$ Hamilton WK. Do let the blood pressure drop and do use myocardial depressants! Anesthesiology $1976 ; 45: 273-4$.

${ }^{6}$ Fletcher R. Coronary disease and anaesthesia. Anaesthesia 1980;35:27-34.

7 Gobel FL, Nordstrom LA, Nelson RR, Jorgensen CR, Wang Y. The ratepressure product as an index of myocardial oxygen consumption during exercise in patients with angina pectoris. Circulation 1978;57:549-56.

8 Vance JP, Smith G, Brown DM, Thorburn J. Response of mean and phasic coronary arterial blood flow to graded hypercapnia in dogs. BrF Anaesth 1979 ;51:523-9.

${ }^{9}$ Kaplan JA, King SB. The precordial electrocardiographic lead $\left(V_{5}\right)$ in patients who have coronary-artery disease. Anesthesiology 1976;45: 570-4.

${ }^{10}$ Anonymous. Haemodynamic monitoring in the intensive care unit. $\mathrm{Br}$ Med f 1980;280:1035-6. 